\title{
CAMINHO DE CHIQUITOS ÀS MISSÕES GUARANÍS (1690 A 1780) (IV).
}

\section{Conclusão.}

\section{IV \\ POSSIVEL SIGNIFICAÇÃO DO FECHAMENTO DO CAMINHO DOS JESUfTAS.}

\section{1. - Contribuiu para romper, artificialmente, a unidade de uma região natural.}

O fechamento do caminho prejudicou a expansão da colonização jesuítica, impedindo que ela se estendesse até las margens do rio Paraguai que ficaram ao abandôno. A margem esquerda, e mesmo uma parte da margem direita, passaram a ser ocupadas pelos portuguêses. Portanto, apesar da perfeita identidade de condições ecológicas entre a margem direita e a esquerda do Paraguai na região de Corumbá que representa uma só planície pantanosa, tropical, estabeleceu-se uma fronteira artificial nessa região.

Por outro lado, o feckamento do caminho criou a estranha situação de duas regiões servidas pela mesma bacia hidrográfica, Chiquitos e Paraguai, ficarem incomunicáveis.

\section{2. - Favoreceu o isolamento da região Oriental Boliviana.}

A região Oriental Boliviana, que desde o início da colonização do Alto Perú não se vinculara à economia do Altiplano, poderia ter se desenvolvido através de uma via de comunicação com o Atlântico. Fechado o caminho para o Atlântico, a região Oriental Boliviana vegetou, sem perspectivas de progresso, até época bem recente. Essa situação do Oriente criou um espírito separatista que pôs em perigo, várias vêzes, a integridade do território boliviano, o que ocorreu por exemplo, por ocasião do movimento revolucionário de julho de 1924 . 


\section{3. - Foi um fator de retardamento da abertura de uma via de acesso à Bolívia, pelo Atlântico.}

Todo o comércio colonial boliviano regular se fazia pelo Pacífico, via Arica ou Callao. Quando o litoral foi perdido, a Bolívia sofreu uma crise que teria sido minorada se desde a época colonial já existisse um intercâmbio com o Atlântico, pela bacia do Paraguai. Aliás o govêrno boliviano sentiu a necessidade de abrir a navegação do Paraguai logo após a independência. Alcide d'Orbigny foi incumbido de estudar a possibilidade de construir um pôrto fluvial na província de Chiquitos. E' interessante confrontar a opinião de d'Orbigny, sôbre a importância da navegação do Alto Paraguai, com as palavras proferidas, um século antes, pelo superior das Missões jesuíticas de Chiquitos, ao solicitar do rei que reabrisse aquela rota fluvial. Referindo-se a pedidos dos colonos de Santa Cruz aos jesuítas para que abrissem o comércio pelo Paraguai, comenta o Superior que

..."rogaron e instaron à $\operatorname{los}$ ( $\mathrm{PP}$. de la Provincia del Paraguay que tomasen con empeño el descubrimiento del camino para el rio Paraguay, y le facilitasen de suerte, que se lograse el comercio con aquella Provincia y Misiones: en que discurrian, tendria su republica y provincia crecidos emolumentos y que hacian juicio seria su total remedio" (81).

Dizia-se d'Orbigny entusiasmado em contribuir para o estabelecimento de um pôrto em Chiquitos:

"en pensant aux immenses avantages qui pourraient résulter de la navigation du Rio Paraguay pour les débouchés commerciaux et pour la civilisation te la province de Chiquitos, je desirais devenir le premier instrument de cette vaste entreprise" (82).

No entanto, passaram-se anos sem que a navegação a vapor fôsse estabelecida no Paraguai. Por decreto de 17 'de novembro de 1832 foi concedido a um argentino, Manuel Luiz Oliden, uma área de 25 léguas de extensão, na província de Chiquitos, sob a condição do beneficiado construir um pôrto em Chiquitos e abrir a navegação fluvial do Paraguai até a Bolívia. Em 1836

\footnotetext{
(81). - Suplica del Padre Superior de las Misiones de Chiquitos al Rei. Manuscrito da Coleção de Manuscritos de Pedro de Angelis, I, 29, 5, 104. Biblioteca Nacional, 1718, cópia.

(82). - - Alcide d'Orbigny, Fragment d'un voylage au centre de P'Ameriquie Meridionale, 1845, página 156 .
} 
Oliden tomou posse das terras, porém a política de Rosas em relação à navegação dos afluentes do Prata era desfavorável aos projetos de Oliden, que, no entanto, desenvolve uma atividade incansável, vindo ao Rio de Janeiro para vencer terras da sua concessão, e indo a Mato Grosso para obter licença: para o filho explorar o rio Otukis. Todos êsses fatos são pormenorizadamente estudados por João Carlos Pinto (83).

Em 1850 Oliden entra em transação com Luiz Vernet, que tenta vender a concessão na Europa e organizar uma companhia, em Hamburgo, para explorar a navegação do Paraguai. Um decreto do govêrno boliviano, de 27 de janeiro de 1853, prometia um prêmio de 10.000 patacões a quem conseguisse chegar, com um navio a vapor, às margens do rio Paraguai, em território boliviano.

Se a navegação entre Chiquitos e o Paraguai já existisse no tempo colonial o problema da livre navegação do rio Paraguai não teria sido tão grave.

João Carlos Pinto sugere no seu artigo, que data de 1861, que o Brasil concedesse à Bolívia o direito de usar o pôrto 'de Albuquerque ou Corumbá como pôrto franco, a fim de evitar os conflitos motivados pelo direito de navegação do rio Paraguai. A Bolívia, que poderia ter sido a única proprietária da bacia do alto Paraguai, via-se dessa maneira numa situação de inferioridade.

\section{4. - Repercutiu no desenvolvimento econômico do Paraguai.}

O fechamento do caminho fluvial dos jesuítas correspondeu, para o Paraguai, à perda de um mercado nas províncias de Chiquitos e Santa Cruz, de uma área de influência, e de possível expansão territorial.

\section{5. - Finalmente, o fechamento do caminho dos jesuítas facilitou a expansão portuguêsa.}

Embora o fechamento do caminho fluvial pelo Paraguai tivesse obedecido a um propósito da monarquia hispânica de impedir a penetração portuguêsa em terras consideradas como espanholas, deu-se exatamente o oposto, como previra, na época, o Superior das Missões jesuíticas de Chiquitos. Êle assim se expressa:

(83). - João Carlơs Pinto, Memória sôbre os Limites do Império comi a Repúbliqa da Bolivia. Revista do Instituto Histórico Brasileira, 1822, Tomo 45. Parte II, páginas 341 e seguintes. 
... "y deseamos saber, ¡de qué modo los han de cerrar los que han informado contra ellos (os caminhos); si ha de ser con cal, canto ó palizada: porque esta será obra como el muro ide la China; pues en distancia de mas de cien leguas, de norte a sur, que tiene esta costa de los Chiquitos, por la parte del Rio Paraguay, no es uno sino varios los caminos que tienen los Portugueses para entrar en nuestras tierras; $y$, aunque se los (cierren, no sabrán ellos abrirlos?" (84).

Mais adiante, comentava o Superior que a vantagem principal do caminho seria a de assegurar a defesa de Santa Cruz:

"Todo lo cual cede en la seguridad de la provincia de (Santa Cruz y de este reino; guardando, como guarda, la nacion de Chiquitos estas costas del Rio Paraguay, de las invasiones de los enemigos mamaluces del Brasil y otros de la Corona". "...los indios de los pueblos fronterizos al rio Paraguay que son San Rafael y S. Joseph salen todos los años á la espia, para prevenir y avisar al gobernador de Santa Cruz, de cualquiera invasion de los Mamalucos...".

O progresso de Chiquitos dependia da abertura do caminho que serviria para os 'padres atingirem as tribos infiéis, e, da ocupação das margens do rio, pelas missões, dependia a defesa de Santa Cruz.

No mesmo documento, supra-citado, o Padre Superior relembra os ataques dos mamelucos a Chiquitos, salientando o papel dos índios das missões, nas vitórias sôbre Ferraes e Manuel Frias, em 1694, e sôbre a bandeira que veio na mesma ocasião e foi desbaratada pelos piñocas. O atrativo da caça ao índio, das minas, e o abandôno das margens do Alto'Paraguai pelos espanhóis, favoreciam as incursões dos portuguêses na região de Chiquitos.

O documento supra-citado (85) refere-se à presença dos portuguêses em Chiquitos, em 1712 e em 1717.

O Padre Burgés, no seu relatório sôbre a situação das missões (86), refere-se a um chefe de mamelucos, Juan Borallo de Almada, que tinha sido derrotado nas vizinhanças do Aperé ou

\footnotetext{
(84). - Súplioa do Padre Superior de Chiquitos ao Rei. Coleção de Manuscritos de Pedro de Angelis, I, 29, 5, 104. Biblioteca Nacional, 1718, cópia.

(85). - Súplica do Padre Superior de Chiquitos no Reí. Coleção de Manuscritos de Pedro de Angelis, I, 29, 5, 104, 1718. cópia.

(86). - Estado de las Misiones de los Padre Jesutas de la Provincia de la America Meridional Ilamados Chiquitos. Cartas Edificantes, 1756. Tomo VII, página 400 e seguintes. Manuscrito da Coleção de Manuscritos de Pedro de Angelis, I, 29, 5, 92. Biblioteca Nacional, s. d., cópia.
} 
São Miguel, pelos chiquitos. Tal fato deve ter sucedido antes de 1715, data provável em que foi escrito o memorial do Padre Burgés. O Superior das Missões de Chiquitos comenta dois encontros com os portuguêses, em 171.2 e 1717, na súplica ao rei para reabrir o caminho pelo Paraguai (87):

“...en año 1712 , en que saliendo á la espia los indios de San Rafael, a distancia de 30 leguas encontraron casualmente con los Portugueses que venian cazando por un monte; y apresando a dos de nuestros indios, los pusieron en collera, y los llevaron al cuartel de su capitan: el cual les hizo varias preguntas por meio de un indio Chiquito, de los que en otras ocasiones habian apresado y llevado al Brasil. Preguntóles quienes eran, y de que pueblo? Respondieron por sus nombres, y que eran hijos de los Padres de San Rafael; como lo podia conocer por las cruces y rosarios que traian al cuello. Preguntó por el numero y nombre de los 'PP. que existian en el, y si era mucha la gente cogiendo el mismo informe de todos los otros pueblos. Preguntó mas, si los castellanos de Santa Cruz isolian frecuentar nuestros pueblos? Respondieron que si, y que era mucha la gente que teniamos".

Acabado o interrogatório, os portuguêses consentiram em libertar os índios. Na mesma ocasião os índios tiveram outro encôntro com os portuguêses, em Chiquitos. Segundo a mesma fonte informativa:

"Otros dos mocetones de nuestros indios encontraron con un Portugues en el monte, $y$ encarando la escopeta à uno de ellos le aguardó y eludio el tiro; y. abalanzandose con gran presteza, le quito la escopeta, con la cual se volvió triunfante á su pueblo, y se la entregó al Padre. Los Portugueses sin mas espera, levantaron luego su cuartel, $y$ á toda priesa se condujeron al Rio Paraguay por jel !mismo camino que habian venido, como lo observaron nuestros indios, que á lo lejos los fueron seguiendo algunos dias". "La otra ocasion fué el año pasado de 1717 , en que saliendo à la espia los indios de dicho pueblo, $y$ juntamente á reducir la nacion d elos infieles; llamados Curucanes, llegaron hasta el $\mathrm{Pa}-$ raguay. Adelantóse un indio Chiquito, con otros pocos indios de las varias naciones que hay en su pueblo ya convertidos, y divisando una canoa, que venia hacia ellos, ise egacharon entre los pajonales, juzgando seria de los infieles que buscaban. Cuando estuvo cerca se levantaron, y vieron á un negro, que traja en la mano un anzuelo para pescar, y otros dos indios que le acompañaban. Vien-

(87). - Suplica del Padre Superior de las missiones do Chiquitos al Reí. Manuscrito da Coleção de Manuscritos de Pediro de Angelis, I, 29, 5, 104. Biblioteca Nacional, 1718, cópia. 
do el negro huyeron los indios que estaban con el Chiquito, diciendo: estos son Portugueses, y, quedando el solo, lo apunto luego el negro con la escopeta; pero se detuvo, oyendo a nuestro indio, que le dijo; no mo tires, pues son cristiano como tu, y no te hago daño. Mostróle una estampa de la Virgen y dejando la escopeta se arrodilló el negro à la imágen. Llegando en este tiempo otros de nuestros indios, les dijo: Esperad, iremos a llamar à "nuestro Capitan".

Nesse interim chegaram uns cento e cinqüenta índios chiquitos às margens do rio e segundo ainda o manuscrito citado:

"No tardaron el llegar tres canoas, en que venian trece portugueses con otros indios de su servicio; cuyo capitan hizo varias perguntas à los nuestros, por medio de uno, que sabia la lengua guarani" (88).

Tendo os portuguêses perguntado quem eram e para que fim vinham àquelas paragens, responderam os índios que eram de Missão de São Rafael e que procuravam infiéis para convertê-los.

"Para lo mismo replicó el Portugues, los buscamos nosotros $\mathrm{y}$,para que venis aqui; (dijo indignado) pues, ya los hemos llevado á todos? A que los Chiquitos respondieron que no sabian mas...".

Inquiriram ainda, os portuguêses, sôbre os chefes dos índios e perguntaram:

"que Padre es ese, y de que pueblo, que va por el rio abajo en un barco? Respondieron: era el P. José de Arce del pueblo de S. Miguel de los Guaranis. Oyendo esto, dijeron 'entre si; estos vienen, sin duda, en busca del $\mathrm{Pa}-$ dre; con to cual volvieron tocando un clarin su negro".

O Padre Juan Patricio Fernandez na sua obra Relacion Historial de los indios que llaman, Chiquitos, página 447, comenta que um português Hernando de Armenta invadiu essa região em 1717.

Referimos, em detalhe, êsses dois episódios porque não são geralmente bem conhecidos.

Os encontros por nós descritos revelam que o acesso a Chiquitos era relativamente fácil para os sertanistas brasileiros,

(88). - Suplica del Padre Superior de las Missiones de Chiquitos al Rei. Manuscrito da Coleção de Manuscritos de Pedro de Angelis, I, 29, 5, 104. Biblioteca Nacional, 1718, cópia. 
afeitos a lutar com as maiòres dificuldades nas suas expedições, principalmente depois que Pascoal Moreira e André de Zuñega estabeleceram um acampamento às margens do Mboteteú, por volta de 1680, fato revelado pelo Professor Afonso de E. Taunay (89).

A descoberta de ouro, por Pascoal Moreira Cabral, no rio Coxipó Mirim, afluente do Cuiabá, desviou o interêsse dos mamelucos da região de Chiquitos para o novo Eldorado. Formaram os portuguêses um arraial num ponto chamado aldeia velha e começaram as lavouras pelas margens do Cuiabá e do Coxipó. Em 1720 o arraial foi transportado para Forquilha. Aos descobridores se juntou, em 1719, a bandeira dos irmãos Gabriel, João, Antônio e Felipe Antunes. A descoberta das minas do Subtil atraira grande número de colonos, paulistas sobretudo. O desenvolvimento do arraial do Senhor Bom Jesus do Cuiabá, que depois se erigiu em vila, criou uma série de problemas de abastecimento nas regiões mineiras, agravados, no caso de Cuiabá, pelas dificuldades de comunicação com São Paulo. Os artigos chegavam a Cuiabá por preços absurdos devido ao custo do transporte fluvial e terrestre, ao constante perigo de deterioração dos gêneros alimentícios e destruição das frotas pelos paiaguás.

Afonso de E. Taunay, em sua História das Bandeiras Paulistas, discorre sôbre os caminhos usados pelos mamelucos, baseado em documento anterior a 1727 .

"Certos sertanistas entravam pela barra do Pardo e a êle remontavam durante quinze dias onde desse navegação. Ali faziam roças. E punham-se a caminhar por terra, em estrada aliás pouco florestada, chegando a Cuiabá em 25 dias.

Havia outros que do Pardo seguiam às cabeceiras do Itiquira, Piajuí, e Piqueri, onde fabricavam canoas com as quais navegavam êstes rios. Em cinco ou seis dias estavam em Cuiabá.

Outros ainda deixavam o Pardo e tomando à esquerda atingiam o Taquari. Navegavam-no durante oito dias até o Paraguai. Subindo por êste chegavam à barra do Cuiabá, que alguns também. chamavam Porrudos.

Mais outros ainda deixavam o Pardo descendo para o Sul até o Ivinheima. Subiam-no até o seu afluente Jaguari, viagem para dezoito dias até um ponto onde deixavam as canoas e faziam lavouras.

(89). - História das Bandeiras Paulistas, pref., 1951, tomo I, página 148 e História Geral das Bandeiras Paullistas, 1928, tomo IV. 
Dêsse pôrto marchavam às cabeceiras do Mboteteu onde fabricavam 'embarcações com as quais desciam em doze dias às águas do Paraguai. Mas neste caminho havia o perigo de encôntro com os guaicurús.

Havia quem preferisse subir o Verde, afluente da direita do Paraná, durante dez zou doze dias, até certo salto, onde ficavam as canoas. Por terra, e ao cabo de 25 dias, chegava-se a um pôrto do Piqueri.

Havia sertanistas, porém, que não faziam conta das terras da bacia do Paraguai. Uma vez saídos do Tietê embicavam pelo Paraná a contra corrente e subiam o Paranaíba” (90).

Refere-se ainda Afonso de E. Taunay a um caminho inteiramente terrestre pelo qual a viagem durava 65 dias; de Itú a Cuiabá.

Com tais caminhos, os artigos exportados de São Paulo para Cuiabá tinham que ser vendidos, neste centro de mineração, por preço muito elevado.

A falta de braços 'e as freqüentes pragas impediam que a lavoura regional suprisse as necessidades do citado centro. Faltava carne, pois nos primeiros anos quase não existia gado nas redondezas de Cuiabá.

Joseph Barbosa de Sá conta que nos primeiros anos após a descoberta das minas, e antes de 1724, houve ocasiões em que se vendeu uma abóbora por quatro oitavas de ouro, e um dourado por sete e oito oitavas de ouro (91). Quando as frotas de São Paulo não chegavam, devido aos ataques dos paiaguás, a situação se tornava grave; de verdadeira penúria. Em 1725, por exemplo, a frota fôra apresada pelos indígenas; tendo-se 'no ano anterior perdido a colheita de milho, agravou-se conseqüentemente a situação. O cronista Joseph Barbosa de Sá comenta, na obra citada, que:

"...chegou-se a dar por hum frasco de sal meya libra de ouro e por falta delle senaó admenistrava o Baptismo a quem carecia o milho que 'se plantava na terra antes de nascer o comiaó os ratos depois de nascido o que escapava dos ratos o destruhiaó os gafanhotos o que chegava a espigar brotava o sabugo sem gram e algum que granava o comiaó os pasaros que era ınecessario colhelo

\footnotetext{
(90). - Afonso de E. Taunay, História das Bandeiray Paulistad, pref., 1951, tomo II, página 21.

(91). - Joseph Barbosa de Sá, Relação das povoaçóens do Curyabá e Mato Grasso de seas princtpios thé os prezentes tempas, in "Annaes da Biblioteca Nacional do Rio de Janeiro", 1904, vol. XIII, página 13.
} 
verde: o que acontecia aos feijoens e a tudo o mais que se plantava na terra" (92).

A destruição das frotas pelos paiaguás era freqüente, nesse período, e, cada vez que isso sucedia, os cuiabanos passavam fome e pagavam preços exorbitantes pelos artigos de primeira necessidade. Em 1726, e por volta de 1729 , as frotas não conseguiram arribar em Cuiabá e:

"venderaóse camizas de alguns lensoes que se desfaziaó a dose oitavas de ouro; a vara de pano de algodam que no pais se tecia a tres e a quatro oitavas e isto era para os amigos que a todos naó chegava; Sal nem para Baptizar e tudo o mais a este respeito" (93).

Pelos Anais de Vila Bela descoberto, por Afonso de E. Taunay, os preços nesse centro mineiro também eram elevadíssimos:

"Um alqueire de milho: $21 \mathrm{grm}$. 516 de ouro.

Um alqueire de feijão: de $35 \mathrm{grm} ., 880$ a $71 \mathrm{grm} .760$.

Uma libra de carne: 7 gr., 172 .

Uma libra de toucinho: 5 gr., 372 .

Um 'prato de sal: $15 \mathrm{gr} ., 344$.

Uma libra de açucar: 21 gr., 516 a 25, 102.

Uma galinha: 21 gr., 516 .

Uma camisa de linho: 21 gr., 516 .

Afonso de E. Taunay atualizou êsses preços calculando os coeficientes relativos entre os valores daquela época e os dos dias de hoje, chegando à conclusão de que uma galinha valia $700 \$ 000$ réis; uma libra de carne (cêrca de meio quilo) $170 \$ 000$ réis; uma libra de toucinho $240 \$ 000$ réis; um quilo de açúcar $600 \$ 000$ réis; um litro de feijão $20 \$ 000$ a $40 \$ 000$ réis; um litro de milho $12 \$ 000$ réis; uma camisa de linha $700 \$ 000$ réis; um côvado de baeta, mais de $300 \$ 000$ réis; um chapéu grosso mais de $300 \$ 000$ réis (94).

A partir de 1727 as mercadorias ainda se tornam mais caras em Cuiabá devido ao governador de São Paulo, Don Rodrigo César, determinar que se estabelecesse um registro para arrecadar impostos sôbre os gêneros que entravam naquela cidade.

\footnotetext{
(92). - Joseph Barbosa de Sá, Releção das povoaçõens do Cuyabá "e Mato Grosso de seos principios thé os prezentes tempos, in "Annaes da Biblioteca Naciona1 do Rio de Janeiro", 1904, vol. XIII, página 15.

(93). - Joseph Barbosa de Sá, Relação das povoaçōens do Cuyahá e Mpto Grasso de seos principios thé os prezentes tempos, in "Annaes da Biblioteca Nacional do Rio de Janeiro", 1904, vol. XIIII, página 26.

(94). - Afonso 'de E. Taunay, Os Pautistas em Mato Grosso (Anal de Vila Bela), in "Revista do Museu Paulista", 1941. Tomo X, páginas 19, 20; 21.
} 
Washington Luís, ao estudar o govêrno de Don Rodrigo César de Menezes (95), revela que além dos impostos pagos no registro de Cuiabá, as mercadorias estavam sujeitas a impostos quando desembarcavam no Rio e Santos e ainda nas passagens dos rios caudalosos. Êsses impostos, chamados de passagem, eram destinados à manutenção de barcas que faziam a travessia dos rios.

Segundo o mesmo autor, os impostos sôbre os escravos, cobrados no registro de Cuiabá, eram os seguintes:

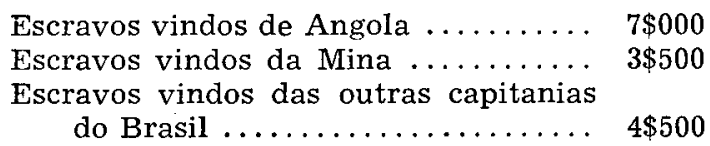

Felipe José Nogueira Coelho, informa que em 1727 cobravam, no registro, por cabeça de gado e por cavalgadura em pêlo, 3 oitavas. As lojas pagavam 50 oitavas e sendo de secos e molhados, 64 oitavas. Em 1731 as tarifas tinham declinado, pois Cuiabá já estava decadente, mas, assim mesmo, eram bem elevadas: oitava e meia por cada carga de sêco de duas arrôbas; meia oitava por carga de molhado; por escravo, duas oitavas; por rez, uma oitava; por cavalgadura, uma oitava. Os direitos eram cobrados em ouro quintado. Afirma ainda o mesmo autor que antes de se abrir o caminho para Goiás, o que se realizou em 1737, o gado era raro em Cuiabá. Valia um cavalo 150 oitavas e meia (96). Tais preços das mercadorias e de mão-de-obra deveriam ser poderosos incentivos para que Cuiabá procurasse centros abastecedores mais próximos do que São Paulo e desejasse evitar os impostos, por meio do contrabando.

Os centros de povoação mais vizinhos de Cuiabá, em 1727, eram Vila Boa de Goiás, a 300 léguas, Mato Grosso, a oitenta léguas, e o arraial de Santo Antônio dos Arayes, a 150 léguas (97). Era portanto natural que Cuiabá tentasse se comunicar com outras regiões mais próximas do que São Paulo, para poder se abastecer e romper o isolamento em que se achava. A busca de uma comunicação seguiu três rumos: para leste, abrin-

\footnotetext{
(95). - Washington Luíls Pereira de Souza, Capitania de São Paulo - Govêrno de Rodrigo César de Menezes, 1918, página 158.

(96). - Nogueira Coelho, Memórias Chronologicas da Capitania de Mato Grosso. -Revista do Instituto Histórico, 1850, Tomo XIII, 2.0 trimestre, páginas $144,148,156$.

(97). - Joseph Barbosa de Sá, Relação das povoaçõens do Cuyabá e Mato Grasso de seos principios thé os prezentes tempos, in "Annaes da Biblioteca Nacional do Rio de Janeiro", 1904, vol. XIIII, página 17.
} 
do uma estrada terrestre para Goiás; para o noroeste, procurando atingir o Pará, pela bacia Amazônica (98); e para oeste, abrindo caminho para Chiquitos. Só têm relação direta com o presente estudo os esforços realizados no sentido de estabelecer comunicação com Chiquitos. Esta província dispunha, em abundância, de gado vacum e cavalar, tecidos, artigos êsses escassos e, portanto, caros em Cuiabá e Mato Grosso. Através de Chiquitos, os cuiabanos poderiam se abastecer, em Santa Cruz de la Sierra, de instrumentos de mineração de lavoura, de sal, enfim de tôda a sorte de gêneros alimentícios. Além do mais, Chiquitos estava mais próximo do que São Paulo, Pará e Goiás.

Segundo Joseph Barbosa de Sá (obra acima citada), em 1740, chegaram notícias a Cuiabá de que missionários castelhanos estavam aldeando índios nas cabeceiras do rio Cuiabá. Em fevereiro, o ouvidor convocou uma junta para se determinar sôbre êsse assunto. Ficou resolvido mandar:

..."homens practicos a investigar as povoaçoens de castelhanoz mais vezinhas para com elles tratar amizades, e fazer que naó desen armas aos Payagoas para nos fazerem guerra troco das fazendas que nos roubavaó como se dizia".

Para a averiguação das povoações de castelhanos, elegeuse Antônio Pinheiro de Faria;

..."com expensas do Senado da Camara do Ouvidor e de algumas pessoas principais que concorreraó com ouro e fazendas mais interesados em que se estabelesese negocio com os castelhanos que era o projeto da impresa, do que impedir desem favor a Payagoazes".

Antônio Pinheiro partiu em abril,

"pasou os rios Paragoai, e Iaurú no lugar chamado as pitas adonde acharaó caminho seguido dos missionarios que ja de antes custumavaó pasar da provincia de Santa. Cruz cá para a nossa parte e reduzir os gentios destes nossos distritos...".

O cronista nos informa que a missão cuiabana foi bem recebida em São Rafael. Antônio Pinheiro de Faria entregou as cartas do ouvidor a pessoas importantes, e ofereceu presentes, sendo o principal um rico ornamento para o altar;

(98). - Jaime Cortesão, Alexandre de Gusmão e o Tratado de Madrid. Parte III. - Antecedentes do Tratado. Tomo II; e Virgílio Correa Filho, Raias de Mato Grosso - Fronteira ocidental, 1926, vol. IV. 


\begin{abstract}
"fizeraó de tudo muita estimaçaó correspondendolhes com ofertas de vacas, cavallos, e outras couzas de menos preso". " $E$ fallandolhes os Portuguezes em materia de negociaçaó de fazendas da eoropa por commutasaó dos efeitos daquelles distritos responderaó que os efeitos que os Portuguezes podiaó della tirar eraó só 'Bois e Cavallos que outra couza naó esperasem e se chegasem alguma preta serlhes hia logo o commercio prohibido". "Sabido isto pelos do Mato Grosso foraó logo alguns a mesma povoaçaó com fazendas a fazer negocios de Bois e Cavallos que havia entaó falta de huma e outra couza em toda esta capitania naó nos deixaraó os Padres Missionarios intrar nem Ihes aceitaraó couza alguma..." (99).
\end{abstract}

A chegada da missão comercial de Antônio Pinheiro a!Chiquitos causou polvorosa em Santa Cruz. O governador desta província, numa série de cartas a Audiência de la Plata, informa que os portuguêses estão localizados muito próximo a Chiquitos e pede recursos para organizar a defesa da província (100) . O Padre Mora, Superior das Missões, informa todos os episódios da chegada dos portuguêses a São Rafael e de suas propostas comerciais, em epístolas ao governador de Santa Cruz, e ao Fiscal da Real Audiência (101). Uma missiva do Padre Palozzi, informa-nos de que as ordens expedidas pela Real Audiência, em 19 de outubro de 1740, mandando expulsar os portuguêses e proibir qualquer comércio, tinham sido cumpridas (102).

Muito provàvelmente, porém, deve ter continuado a existir comércio clandestino, de gado e outros gêneros, entre Chiquitos e Mato Grosso, pois havia condições favoráveis para tal intercâmbio. As dificuldades do percurso entre Cuiabá e Chiquitos, conforme já acentuamos, se bem que grandes, eram menores do que as existentes nos demais caminhos que ligavam Mato Grosso aos outros centros.

Em 1792 Nicolas Arredondo escrevia, ao governador de Chiquitos, que tinha recebido cópia do ofício de 19 de julho de 1792, do governador Intendente do Paraguai, sôbre um pro-

\footnotetext{
(99). - Joseph Barbosa de Sá, Relação das Povoaçóens do Cuylabá e Mato Grosso de seos principios thé os prezentes tempos, in "Annaes da Biblioteca Nacional do Rio de Janeiro", 1904, vol. XIII, páginas 39 e 40.

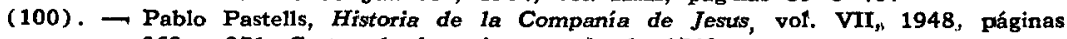
369 e 371, Cartas de fevereiro e maio de 1740.

(101). - Pablo Pastells, Historia de la Companía de Jesuss, 1948j vol. VII, páginas 386 e 388 , Cartas de 12 e 15 de setembro de 1740 .

(102). - Pablo Pastells, Historia de la Companía de Jesus, 1948, vol. VII, página 412, Carta de 28 de dezembro de 1740 .
} 
jeto de abrir caminho entre Chiquitos e o Paraguai. Informava que suspendera a abertura do caminho porque:

..."si los Portug.s viesen facilitada con tal camino su interna.on, en esos Pueblos (de Chiquitos) P.a el contravando $y$ robos que acostumbran dilatarian ei abandono de aquellos dos establecim.tos.". (Albuquerque e Nova Coimbra" (103).

O intercâmbio entre Chiquitos e Mato Grosso deve ter progredido, apesar das proibições do govêrno espanhol, porque atendia aos interêsses das duas regiões acima referidas e ao da corôa portuguêsa. As instruções régias para o governador e capitão general da capitania de Mato Grosso, Luís de Albuquerque de Melo Pereira e Cáceres, de 13 de agôsto de 1771, patenteiam o desêjo da monarquia portuguêsa de manter o comércio com as antigas missões de Moxos e com as demais das fronteiras de Mato Grosso:

"...terá V. Sa. en todo o cuidado em assinar o dito comercio por todos os meyos que the forem possiveis de tal isorte porem e com tal desfarse que não paressa que V. Sa. o promove e menos que tem ordem para assim o fazer".

"Nestas circunstancias bem verá V. Sa., gue hum dos meios para conseguir este fim hé o de agazalhar, de receber com agrado os habitantes das aldeas castelhanas confinantes dessa Capitania particularmente os passadores de fazendas, que sempre cresserão em numero a proporção que o comercio aumentar. $\mathbf{E}$ destes podera $V$. Sa. tambem haver notivias de tudo quanto se passar nos Dominios de Castela". "...estabelecer entre os Portuguezes e os habitantes das soberditas aldeas e Missoens huma amizade e confiança mutua, de sorte que por mais que trabalhe o governo de Castella a vedar acomunicação entre elles e nós, achem sempre aquelles povos mais utilidade e mayor ventagem em nos comonicar do que em sbedecer as Leys que o prohibem" (104).

E' interessante se observar que a instrução régia 'acima citada se refere a uma carta de ofício de Pombal a Dom Antônio Rolim de Moura, de 7 de julho de 1757, recomendando-lhe que

\footnotetext{
(103). - Documentos Refativos al nuevo camino proyectado entre el Paraguay y Chiquitos. Carta de Nicolas Aredondo al Gobernador de Chiquitos. Coleçāo de Manuscritos de Pedro de Angelis, I, 29, 6, 41. Biblioteca Nacional, 25 de dezembro de 1792, cópia.

(104). - Instrução Régia para o governador e capitão General Lutiz de Albuquerque. Revista "O Archivo", 1904, Ano I, vol. I, XI, páginas 18 e 19.
} 
restrinja o comércio entre as missões espanholas e Mato Grosso para evitar que os jesuítas acusassem os portuguêses de serem contrabandistas, pois nessa época as relações eram tensas entre Portugal e Espanha. Tais recomendações referiam-se à região de Moxos porém era provável que o contrabando se praticasse também na fronteira sul.

O governador Luiz de Albuquerque de Mello Pereira e Cáceres propôs ao govêrno português a ocupação da margem direita do Paraguai, de Jaurú ao Fêcho dos Morros, em represália aos avanços espanhóis na região de Moxos.

O presídio de Coimbra e o pôrto de Albuquerque, depois Corumbá, foram fundados com êsse objetivo de ocupar a margem direita do Paraguai, na região da província de Chiquitos. A ocupação portuguêsa da margem direita do Paraguai foi estudada detalhadamente por muitos autores, no passado e no presente, entre os quais destacaremos Leverger (105), Virgílio Correa Filho (106), Jaime Cortesão (107), Rio Branco (108) entre os autores de língua portuguêsa.

A obra de Pedro de Angelis (109) é um verdadeiro repositório de informações sôbre êsse tema.

$\mathrm{Na}$ Coleção de Manuscritos de Pedro de Angelis encontramos um documento classificado como original, anônimo, 'que descreve as povoações e fortificações portuguêsas de Assunção para o norte (110), Notícias de Cuiabá e Mato Grosso, anônimo (111), 'e uma Informação sôbre a Capitania de Mato Grosso por Ricardo Franco de Almeida (112). Outra importante fonte de informação é Manuel Felix de Azara (113).

\footnotetext{
(105). - Leverger, Documentos officizes Portuguezes e Hespanhois Relativos aos Limites do Império na Provincia de Mato Grosso, manuscrito 343, 21, 5. Arquivo Histórico do Ministério das Relações Exteriores.

(106). - Virgílio Correa Filho, Mato Grotso, 1922 - As Raias de Mato Grosso: Fronteira Meridional, 1926, vol. III.

(107). - Jaime Cortesãq. Alexandre de Gusmão e o Tratado de Mato Grosso (Obra em publicação pelo Instituto Rio Branco do Ministério idas Relações Exteriores).

(108). - Rio Branco, Obras do Barão do Rio Branco, Qu^estões de Limites, exposições de Motivos. 1947, vol. IV.

(109). - Pedro de Angelis, Colección de Obras y Docarmentos Relativos a la Historia Antigua y Moderna del Rio de la Plata, 1836.

(110). - Relacion de las poblaciones y fortificaciones que han formado los Portuguteses de la Asumpcion hácia el noirte. Manuscrito da Coleção de Manuiscritos de Pedro de Angelis, I, 29, 6, 22, Biblioteca Nacional, s. d.. original.

(111). - Noticias de Cuyabá y Mato Grosso. Manuscrito da Coleção de Manuscritos de Pedro de Angelis, I, 29, 6, 48, Biblioteca Nacional, s. d., cópia.

(112). - Memotia e Informe dado al gobierno isobre la capitania de Mato Grosso. por Ricardo F. Almeida Sena. Coleção de Manuscritos de Pedro de Angelis, I, 29, 6, 49, Biblioteca Nacional, jameiro de 1800, cópia.

(113). - Memorias sobre el estado rural del Rio de Plata en $1801_{h}$ demarcacion de límites entre el.Brasil y Paraguay, 1847.
} 
Ao nosso assunto porém só interessa salientar que, a partir da missão comercial de 1740 , se estabeleceu contacto entre Mato Grosso e as aldeias de Chiquitos e desde então se desenvolveu o comércio clandestino e, por fim, em 1778, fundou-se o pôrto de Albuquerque, depois Corumbá, na margem direita do Paraguai, aproximadamente no local onde os jesuítas tinham pretendido fundar um pôrto espanhol.

Cumpriram-se portanto as predições do Padre Superior das Missões de Chiquitos proferidas em 1718, na ocasião do fechamento do caminho entre Chiquitos e Assunção.

\author{
EULALIA MARIA LAHMEYER LOBO \\ Livre-docente de História Americana da Faculdade \\ Nacional de Filosofia. \\ $*$
}

BIBLIOGRAFIA CITADA.

FONTES PRIMÁRIAS.

Manuscritos.

ADICION à la Relacion del víage que híziéron los PP, Joseph Francísco de Arze, y Bartholomè Blendez nor el río Paraguay à los Chiquitos, en que se refière en breve resumen las muertes de los Padres, segun notícías adquírídas de los Indios Infiéles Payaguàs que passaron à nuestra Doctrinas, y están en ellas. s. d., não assinado, cópia. Rio de Janeiro. Biblioteca Nacional. Coleção de Angelis, I, 29, 5, 96.

BREVE relacion del víage que hizieron por el Rio Paraguay arriba 5 Padres y un Hermano el año 1708 por orden de N.ero. $P$. General, por Joseph fran.co de Arce, S. Mig.l y Abril 5 de 1713. Cópia, seguida de comentários inacabados e não assinados. Idem I, 29, 5, 95.

CARTA de Nicolas de Arredondo ao governador de Chiquitos. Buenos Ay.s, 25 de Diz.re, 1792. Es-copia Joseph Ortiz. In: Documentos relativos al nuevo camino proyectado entre el $\mathrm{Pa}$ raguay y Chiquitos. Idem, I, 29, 6, 41.

CEDULA real que exhonera a los Indios de Chiquitos del pago de tributos, por el espacio de 20 años 1706. Original. Idem, I, $29,5,100$.

CERTIFICACION del gobernador de Santa Cruz de la Sierra, de cuatro reducciones de Indios Chiquitos fundadas por los $P$. P. de la Compañia de Jesus, veinte dias del imes de Julio de mill y seiscentos, y nouenta y nueve. Original, Idem, I, 29, 590.

Consultas que se hisieron en las Juntas del Puebo de San Xavier donde se trataron todo los concernente à las Misiones fecha em 11 de Julio de 1708. Cópia. Idem, I, 29, 5, 101. 
DIARIO de un viage emprendido en 1703 , para descubrir una comunicacion entre las Misiones del Paraguay y las de Chiquitos. Cópia de De Angelis. Idem, I, 29, 5, 91.

DIFICULTADES que al presente se ofrecen acerca del viage de los PP en balsas, por el Rio Paraguay arriba, á los Itatines, y de alli al parage del Puebo Nuevo de los Chiquitos por el P. Pedro de Lascamburú, fecho en 27 de junio de 1692. Cópia de De Angelis. Idem, 'I, 29, 5, 89.

DoCUMenTos officiaes Portuguezes e Hespanhóes relativos aos Limites do Imperio na Provincia de Mato Grosso compiladas de ordem do Illmo. e Exmo. Snr. Antonio Francisco de Paula Hollanda Cavalcanti d'Albuquerque, Ministro e Secretario d'Estado dos Negocios da Marinha, pelo Capitão de Fragata da Armada Nacional e Imperial Augusto Leverger. Brasil. Ministério das Relações Exteriores. Arquivo Histórico, $343,2,5$.

ESTADo de las Misiones de los Padres Jesuitas de la Provincia de Paraguay entre los Indios de la America Meridional llamados Chiquitos, $y$ de las otras misiones establecidas sobre los Rios de'Parana y Uruguay en el mismo continente sacado de un Memorial Español embiado à su Magestad Catolica por el Padre Francisco Burges, de la Compañia de Jesus, Procurador general de la Provincia de Paraguay. S. d., cópia. Rio de Janeiro. Biblioteca Nacional. Coleção De Angelis, I, $29,5,92$.

ITINERARIO que comienza desde la ciudad de Santa Cruz de la Sierra, pasando por la cordillera propriamente dicho, por los Pueblos de aquellas Misiones, por el curato del Sauce, por la Villa de la Laguna, hasta la ciudad de Chuquisaca quq por otro nombre la llaman de la Plata; y desde dicha ciudad, siguiendo el camino real de las Postas, hasta la capital de Buenos Ayres, és Asavèr Buenos Ayres, 14 de Julio del año de 1802 (por) D. José Sourryere de Souillac. Cópia. Idem, I, $29,6,40$.

MEMORIA o Informe dado al Gobierno sobre la Capitania de Mato Groso, por Ricardo Franco de Almeida Serra, Teniente Coronol Ingeniero; en 31 de Enero de 1800. Cópia. Idem, I, 29, 6,49 .

NóricIAS de Cuyabà y Matogroso. S. d., cópia, idem, I, 29, 6, 48.

REAL Provision (de la Audiencia de la Plata. En que, por órden del Señor Virrey de estos reinos del Peru, ete., mandase cerrar el camino y comercio por el Rio Paraguay, que intentan los P. P. de la Compañia de Jesus de la Provincia del Paraguay por las Misiones de los Chiquitos. Cópia de De Angelis. Nesta pasta existem vários outros documentos, entre os quais uma Súplica do padre Superior das Missóes de Chiquitos, 1716 a 1718. Idem, I, 29, 5, 104.

KFLACION breve del estado en que se halla la Mission de los Chiquitos y su primer origen el año de 91, ̀̀ primer de deciem- 
bre, que llegó el P. Joseph Francisco de Arce al pueblo de los Piñocas cincuenta leguas distante de Santa Cruz. Cópia de De Angelis. Idem, I, 29, 5, 88.

RELACION de las poblaciones $y$ fortificaciones que desde la linea de Alexandre sexto al poniente han formado los Portugueses, comprehendiendo solamente lo que se han internado desde la altura de la Asumpcion del Paraguay havia el Norte. Original (?). Idem, I, 29, 6, 22.

RFLACION de un viage a los Chiquitos. Duas cartas do Padre Superior Bartholomè Ximenez ao Padre Provincial, 1703 e 1704. Cópia (?). Idem, I, 29, 5, 97.

RFLACION de un viage al rio (Paraguay, 1705, ao Pe. Prov.l Lauro Nuñez por Juan Patricio Fernandez. S. Raphael febrero 3 de 1705. Original. Idem, I, 29, 5, 99.

StlPlica del Pe. Superior de estas Misiones de los Chiquitos sobre la dicha provincia, 6 de Octubre de 1718 años. Cópia. Idem, I, 29, 5, 104 .

VARIOS puntos para responder à un memorial del Gobernador de Sta. Cruz y su Cavildo. S. d., original (?). Idem. I. 29. 6, 14.

Publicações.

aCtas da Camara da Villa de são PaUlo, São Paulo, Arquivo da Câmara Municipal de São Paulo, 1914-1951, 70 v. (v. consultado: 2. 1596-1622).

AZARA, Manuel Felix, Memorias sobre el estado rural del Rio de La Plata en 1801, demarcacion de limites entre el Brasil y el Paraguay à ultimas del siglo XVII, e informes sobre varios particulares de la America Meridional española... los publica su sobrino don Agustin Azara... bajo la dirección de don Basilio Sebastian Castellanos de Losada... Madrid, Imprenta Sanchez, 1847.

CARTAS edificantes, $y$ curiosas, escritas de las missiones estrangeras y de Levante, por algunos missioneros de la Compañia de Jesus. Madrid. En la Oficina de la viuda de M. Fernandez, imprenta, 1753-1757. 16 v. (v. consultados: $7,9,15$ ).

RANDEIRANTES NO PARAGUAY: século XVII (documentos inéditos). (São Paulo, Divisão do Arquivo Histórico de São Paulo). 1949. (Coleção do Departamento de Cultura, v. XXXV).

CHARlevoix, Pedro Francisco Javier de, Historia del Paraguay... con las anotaciones $y$ conecciones latinas del $P$. Muriel traducida al castellano por el P. Pablo Hermández. Madrid, V. Suárez, 1910-1916. 6 v. (Colección de libros y documentos referentes à la historia de America, t. XI-XIII, XV, XVI-XVIII) .

CORTESÃO, Jaime, Alexandre de Gusmão e o Tratado de Madrid (1750) ...organizado e comentado por Jaime Cortesão. Rio de Janeiro, Instituto Rio Branco, 1950 - conteúdo Pt. 1, t. 1. Alexandre de Gusmão e o Tratado de Madrid (1695-1735) por Jaime Cortesão. t. 2. Alexandre de Gusmão e o Tratado de Madrid (1735-1753) por Jaime Cortesão. 
Pt. 2, t. 1 Obras Várias de Alexandre de Gusmão, organizadas e comentadas por Jaime Cortesão. t. 2. Documentos biográficos, organizados e comentados por Jaime Cortesão. Pt. 3, t. 1. Antecedentes do Tratado, documentos organizados e anotados por Jaime Cortesão.

Pt. 4, t. 1. Negociações do Tratado, documentos organizados e anotados por Jaime Cortesão. - t. 2. Negociações do Tratado, documentos organizados e anotados por Jaime Cortesão (no prelo). - Pt. 5. Execução do Tratado, documentos organizados e anotados por Jaime Cortesão (no prelo) (v. consultado Pt. 3, t. 1).

DE ANGELIS, Pedro, Colección de Obras y Documentos relativos a la Historia Antigua y Moderna de las Provincias del Rio de la Plata, ilustradas con notas y disertaciones... Buenos Aires, Imprenta del estado, 1836-1837. $6 \mathrm{v}$.

DíAZ DE GUZMÁN, Ruy, La Argentina. Buenos Aires, Angel Estrada y Cia. S. A. editôres, 1943.

FERNANDEZ, Juan Patricio, Relacion Historial de las Missiones de los Indios que llaman Chiquitos, que están à cargo de los Padres de la Compañia de Jesus de la Provincia del Paraguay... En Madrid, Manuel Fernandez, 1726.

LOZANO, Pedro, Descripcion corografica del Gran Chaco Gualamba, Tucumán, Instituto de Antropologia 1941 (Universidad Nacional de Tucumán, publicación n. 288 - Departamento de Investigaciones Regionales).

MANUSCRITOS DA COLEÇÃO DE ANGELIS: vol. 1 Jesuítas e Bandeirantes no Guairá (1549-1640); introdução; notas e glossário por Jaime Cortesão. Rio de Janeiro, Imprensa Nacional, 1951 (Biblioteca Nacional).

__ Jesuitas e Bandeirantes no Itatim (1596-1760); introdução, notas e glossário por Jaime Cortesão. Rio de Janeiro, Imprensa Nacional, 1952. (Biblioteca Nacional).

— Tratado de Madrid, Antecedentes, Colônias do Sacramento... (1669-1749); introdução, notas e sumários por Jaime Cortesão. Rio de Janeiro, Imprensa Nacional, 1954 (Biblioteca $\mathrm{Na}$ cional).

NUUNEZ CABEZA DE VACA, Alvar, Naufragios y comentarios... Buenos Aires, Espasa Calpe Argentina s. a., 1942.

FAES LEME, Pedro Taques de Almeida, Nobiliarchia paulistana histórica e genealógica... 3 ed. São Paulo, Livraria Martins, 1953-1954, 3 v. (v. consultado 2).

FASTELLS, Pablo, Historia de la Compañia de Jesus en la provincia del Paraguay (Argentina, Paraguay, Uruguay, Perú, Bolivia y Brasil) según los documentos originales del archivo general de Indias, extractados $y$ anotados por Pablo Pastells, Madrid, V. Suárez, 1912-1949. 8 v. em 9 (v. 6-8 "Continuación por F. Mateos". Publicado como v. 5 da série "Biblioteca Missionalia Hispanica" con imprenta: Madrid, Consejo de In- 
vestigaciones Cientificas, Instituto Santo Toribio de Mogrovejo, v. consultados: 4,5 e 7 ).

SCHMIDEL, Ulrich, Viage al Rio de La Plata y Paraguay. Buenos Aires, Imprenta del Estado, 1836, 1a. ed., (Terceiro volume da obra de De Angelis: Coleccion de Obras y Documentos relativos a la Historia Antigua y Moderna de las Provincias del Rio de la Plata).

VIEDMA, Francisco de, Descripción geografica y estadistica de la Provincia de Santa Cruz de la Sierra... 1a. ed. Buenos Aires, Imprenta del Estado, 1836 (Terceiro volume da obra de De Angelis: Coleccion de Obras y Documentos relativos a la Historia Antigua y Moderna de las Provincias del Rio de La Plata).

\section{FONTES CARTOGRÁFICAS.}

FITRLONG CARDIFF, Guillermo, Cartografia Jesuítica del Rio de La Plata. Casa Jacobo Penser Ltda., Buenos Aires, 1936. (Facultad de Filosofia y Letras, Publicación del Instituto de Investigaciones Historicas $n$. LXXI).

HERNANDEZ, Pablo, Missiones del Paraguay, organizacion social de las doctrinas guaraniés de la Compañia de Jesus. Barcelona, Gustavo Gili editor, 1913. 2 v.

JOHNSON, J. M., Philip's General Atlas, George Philip and Son. Liverpool, Edinburgh, Dublin, London, 1858.

MíTRAUX, Alfred, "Indians of the Gran Chaco", Handbook of South American Indians (Washington. Smithisonian Institute, Bureau of American Ethnology, Bulletin 143 (1946-1950. 6 v.), v. 1: $197-370$.

hlO BRANCO, José Maria da Silva Paranhos, barão de, Questão de Limites Brasileira Argentina, New York, The Knickerbocker Press, 1894, v. 6, maps.

\section{FONTES SECUNDÁRIAS.}

ASTRAIN, Antonio, Tistoria de la Compañia de Jesus en la Asistencia de España, Madrid, Administracion de la Razon y Fe, 19131920. 7 v. (v. consultado: 6).

BACKER, Aloys e Augustin de, Bibliothèque de la Compagnie de Jesus, 1.ère partie, nouvelle édition par Charles Sommervogel. Bruxelas, O. Schepens, 1890-1900. 9 v. (v. consultado: 3).

HUARQUE DE HOLANDA, Sérgio, Expansão paulista em fins do século XVI e princípios do XVII... São Paulo (Serviço de documentação do Instituto de Administração), 1948 (Publicação n. 29).

CALógeras, Pandiá, As Minas do Brasil e sua legislação. Rio de Janeiro. Imprensa Nacional, 1904.

C.ANABRAVA, Alice Piffer, o Comércio português no Rio da Plata... (1580-1640). São Paulo, 1944. "Separata do Boletim de His- 
tória da Civilização Americana; n. 2, Faculdade de Filosofia. Ciências e Letras da Universidade de São Paulo".

CORReA FILHO, Virgílio, Mato Grosso. Rio de Janeiro, Coeditôra brasílica (pref. 1920).

As raias de Mato Grosso. São Paulo, Secção de Obras d'“O Estado de São Paulo", 1925-1026. 4 v. (v. 3: Fronteira meridional; v. 4: Fronteira ocidental).

DUMfNGUEZ, Manuel, El alma de la raza. Asunción. C. Zamphirópolos, 1918. (Biblioteca paraguaya del Centro de estudiantes de derecho. (v. 1)).

ELLIS JƯNIOR, Alfredo, o bandeirismo paulista e o recúo do meridiano, 3a. ed., São Paulo, Companhia Editôra Nacional, 1938. (Biblioteca Pedagógica Brasileira. Sér. V. Brasiliana v. XXXVI).

FINOT, Enrique, Historia de la conquista del Oriente Boliviano, prólogo de Roberto Levillier, Buenos Aires, Casa Editôra, Libreria Cervantes, 1939.

GANDIA, Enrique, Historia critica de los mitos de la Conquista. Madrid, Buenos Aires, Editôres Juan Robleda y Compañia, 1929. Historia de Santa Cruz de la Sierra: una nueva Republica en Sud America. Buenos Aires, Talleres graficos argentinos de L. J. Rosso, 1935.

IiARING, C. H., Comercio y navegación entre España y las Indias. México, Fondo de Cultura Economica, 1939.

MELLo, Raul Silveira de, História do Forte de Coimbra, (1500 a 1718), Rio, Imprensa do Exército, 1958, v. 1.

MOLina M., Placido, Historia del obispado de Santa Cruz de la Sierra; capítulos relacionados con la cuestion del Chaco Boreal. Apêndice. Sucre, 1936. La Paz, Ed. Universo, 1938.

MORNER, Magnus, The political and economic activities of the Jesuits in the La Plata region, the Habshurg era, Stockholm, Victor Pettersons Bokindustri Aktiebolag, 1953 (Library and Institute of Ibero American Studies).

ORBIGNY, Alcide, Fragment d'un voyage au eentre de l'Amérique Méridionale. Paris, Bertrand, 1845.

OTERO, Gustavo Adolfo, La vida social del coloniaje. La Paz, Editorial La Paz, 1942.

PALACIO, Ernesto, Historia de la Argentina, 1515-1938. Buenos Aires, Alpe, 1954

PEÑALOZA, Luis, Historia Economica de Bolivia. La Paz, Imprenta El Progreso, 1953-1954. $2 \mathrm{v}$.

PEREIRA DE SOUZA, Washington Luís, Capitania de São Paulo; govêrno de Rodrigo César de Menezes. São .Paulo; Tip. Casa Garraux, 1918.

F.IO BRANCO, José Maria da Silva Paranhos (barão do), Questões de limites, exposições de motivos. Rio de Janeiro (Ministério das Relações Exteriores), 1947 (Obras do Barão do Rio Branco, V). 
TAUNAY, Alfredo d'E., História das bandeiras paulistas... São Paulo, Ed. Melhoramentos, pref. 1951.

- História geral das bandeiras... São Paulo, Tip. Ideal, H. L. Canton, 1924-1950. 11 v. (v. consultados: 4 e 6).

\section{Anais e revistas.}

CARTAS régias de 1771 a 1803 relativamente ao govêrno da capitania de Mato Grosso: Instrucção con que Sua Mage. mandou passar à capitania de Mato. Illmo. exmo. Sr. Luis de Albuquerque de Mello Pereira e Caceres, governador e cap. general della. "O Archivo", Cuyabá, 1: 17-22, 1904.

COELHO, Felipe José Nogueira, Memorias chronologicas da capitania de Mato Grosso principalmente da Provedoria da Fazenda Real e Intendencia do ouro. "Revista de Historia e Geographia ou Jornal do Instituto Histórico e Geographico Brazileiro", Rio de Janeiro, 13 (2.0 trimestre), 1850.

PIREIRA PINTO, João Carlos, Memoria sobre os limites do Imperio com a Republica da Bolivia. Revista Trimensal do Instituto Histórico, Geographico e Ethnografico do Brazil, Rio de Janeiro, 45 (2): 327-550, 1882 .

SA', Joseph Barbosa de, Relação das povoaçoens do Cuyabá e Mato Grosso de seos principios the'os prezentes tempos. Annaes da Bibliotheca Nacional, Rio de Janeiro 23 (1901) : 5-58, 1904.

TAUnAY, Alfredo d'E., Paulistas em Mato Grosso. 1 a 12. Anais de Vila Bela. 12 a 14. São Paulo, Imprensa Oficial do Estado, 1941: Museu Paulista Anais, Tomo X. 